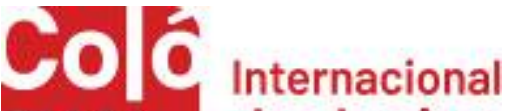 \\ gur de design \\ EDIÇĀO 2020
}

\section{Fibra de piaçava: Possibilidades no Design Sustentável e Economia Circular}

Igor Cesar Rosa da Silva;

Ana Karla Freire de Oliveira

resumo:

Este artigo tem por objetivo apresentar a fibra de piaçava, em especial seus resíduos, enquanto recurso material no campo do design sustentável e da economia circular. Este texto faz parte de uma pesquisa de mestrado em andamento no Programa de Pós-Graduação em Design da Universidade Federal do Rio de Janeiro. É apresentado e discutido o processo de fabricação de vassouras a partir desta fibra e em especial, a geração de resíduos da piaçava, que podem se tornar um recurso alternativo no desenvolvimento de artefatos menos agressores ao meio ambiente. A relevância deste estudo consiste na reflexão sobre a utilização de resíduos de fontes vegetais na fabricação de novos materiais, em especial, ecocompósitos de matriz polimérica de fontes renováveis, analisando por fim, sua utilização na geração de produtos de design sustentável. A fibra de piaçava é analisada sob a ótica do design sustentável e da economia circular, traduzindo-se em um estudo de impactos positivos para o meio ambiente e sociedade em geral.

\section{palavras-chave:}

Design industrial; Materiais; Fibra de piaçava; Resíduos de fibras vegetais; Economia Circular 


\section{Introdução}

Atualmente, é vista uma frequente pressão organizada pela sociedade a fim de exigir um ambiente mais sustentável e responsável em empresas, governos e ONGs (CÔRREA e XAVIER, 2013, p. 2). Com esta preocupação, palavras como "Refletir, Responsabilizar-se, Respeitar, Reduzir, Reutilizar, Reparar, Reciclar e Repassar" passam a fazer parte de um processo de transformação mais profunda diretamente relacionada com a necessidade de mudar a forma de consumir (UOL, 2011).

A partir de pesquisas realizadas e acompanhando as necessidades contemporâneas da sociedade em relação à sustentabilidade, nota-se um interesse por uma mudança constante e que permita a busca por novos materiais e produtos que causem menos prejuízos ao meio ambiente. É o caso, por exemplo, dos materiais compósitos reforçados por fibras vegetais, que atualmente tem gerado um grande interesse por parte dos pesquisadores e profissionais da área, isto se justifica pelas vantagens apresentadas, em seu uso, tanto para o homem quanto para o meio ambiente.

A busca por novas aplicações das fibras naturais vem aumentando a partir do interesse de pesquisadores, que buscam aplicações em diversos campos, tais como: construção civil, arquitetura, design, área médica, mobiliário, etc. GIACOMINI (2003, p.21), afirma que as fibras naturais possuem vantagens por serem recursos provenientes de fontes renováveis, que em geral possuem boas propriedades mecânicas, são biodegradáveis e apresentam baixo custo.

Este texto faz parte de uma pesquisa de mestrado que se encontra em desenvolvimento no Programa de Pós-Graduação em Design (PPGD) da Universidade Federal do Rio de Janeiro, Escola de Belas Artes. O objetivo do estudo consiste em analisar a viabilidade de uso do ecocompósito formado por resíduos de fibra de piaçava (Attalea funifera martius) e resina poliuretana derivada do óleo de mamona (Ricinus communis) enquanto material aplicável ao universo do design sustentável.

Neste artigo, será apresentada e discutida as potencialidades da fibra de piaçava, em especial, a utilização de seus resíduos gerados no processo de fabricação de vassouras de fábricas visitadas. Tais resíduos serão analisados à luz do design sustentável e da economia circular, visando apresentar suas potencialidades de uso nessas áreas de pesquisa e atuação.

\section{Design \& Materiais: Uma breve análise da relação entre as áreas}

Uma importante reflexão sobre a relação Design \& Materiais é feita por EVBOUMWAN et. al. (Apud WALTER, 2006, p.74) na qual os autores afirmam que "um produto permanece um conceito, uma ideia, ou talvez um desenho, se nenhum material estiver disponível para convertê-lo numa entidade tangível”. Desta maneira, um produto necessariamente depende de um material para torná-lo físico e um processo de fabricação para dar-lhe forma.

Surge então o termo materializar, que segundo DIAS (2009, p. 35) refere-se a dar ou assumir uma consciência, concretizar algo, no sentido de transformar em realidade. Neste contexto, autores conceituados da área de Design \& Materiais, como ASHBY e JOHNSON (2011, p. 55), consideram que "materiais consistem na matéria de que é feito o design de produtos" ou ainda "a escolha do material é influenciada pela natureza do usuário: crianças, jovens ou idosos".

Desta forma, é por meio dos produtos que interagimos com os materiais e através desta interação o usuário estabelece conexões emocionais com o artefato utilizado, associando o objeto a determinadas características, como a textura, cheiro, brilho, etc (ASHBY e JOHNSON, 2011, p. 81). São várias as propriedades e qualidades atribuídas a um produto, o que os tornam peça fundamental para o aperfeiçoamento ou mudança na qualidade de vida das pessoas.

Nesta perspectiva, GOMES FILHO (2006, p. 151) em sua obra Design do Objeto - Bases Conceituais afirma que "as bases conceituais se relacionam com as três funções básicas e dizem respeito aos materiais como componentes físicos que constituem um produto". Essas três funções que o autor se refere são: conjunto de fatores, propriedades e características dos materiais e a categorização conceitual dos materiais. Entende-se com isso que a escolha dos materiais é determinada a partir da idealização, concepção e desenvolvimento do produto.

Além das funções básicas atribuídas aos materiais na concepção de um produto, esse vínculo permite estabelecer uma característica estética ou mesmo uma personalidade ao produto. Segundo ASHBY e JOHNSON (2011, p. 174): 
O modo como pensamos em materiais ou em materialidade depende de contexto, cultura, demografia, estilo, tendência e outros. É difícil para as pessoas falarem especificamente sobre os materiais que são usados para fazer as coisas que compram, é tarefa do designer expressar a materialidade de cada objeto [...].(ASHBY e JOHNSON, 2011, p.174)

Vários são os fatores que podem influenciar o produto, partindo da elaboração das ideias à escolha dos materiais até o objeto final e neste cenário o designer precisa ser capaz de dar uma significação a um produto por meio da relação dos materiais e o design. Os autores continuam:

[...] Combinadas, materialidade e eficiência permitem ao designer desenvolver produtos que sejam inovadores e, ainda assim, expressões totalmente tangíveis e otimizadas de uma ideia. Essa é a ideia que chegará ao mercado. (ASHBY e JOHNSON 2011, p. 4).

Neste sentido os autores expressam a ideia de materialidade, como sendo um modo de construção com conexões táteis, envolvendo a criação do objeto e a própria experiência de percepção do usuário sobre o produto.

A importância dos materiais para o design é reforçada junto ao pensamento projetual. COHEN (1974, p.1) define para o termo materiais as substâncias com propriedades que possibilitem o desenvolvimento e construção de máquinas, estruturas, dispositivos e produtos. Para o autor,

A ciência e engenharia de materiais preocupam-se com a geração e aplicação de conhecimentos relacionando a composição, estrutura e processamento de materiais às suas propriedades e usos [...] (COHEN, 1974, tradução nossa).

Assim a Ciência e a Engenharia de Materiais ocupam-se de pesquisa e produção de materiais capazes de serem convertidas em produtos, estabelecendo uma relação direta com o design. A trajetória dos materiais interferiu e interfere no cotidiano da humanidade, a partir de descobertas do seu aperfeiçoamento é possível conceber novos produtos ou melhorar os já existentes.

Esta pesquisa de mestrado que se encontra em andamento e que originou este artigo, analisa os materiais compósitos oriundos de recursos sustentáveis. Neste sentido, é oportuna uma definição a respeito destes materiais, como a de CALLISTER (2002, p. 4) que aponta que os compósitos consistem em combinações de dois ou mais materiais diferentes [...]", sendo sua principal característica o resultado obtido na combinação de cada material que o compõe.

Os materiais de origem renovável podem ser fonte para a fabricação de compósitos menos agressores ao meio ambiente. É o caso, por exemplo, dos ecocompósitos formados por fibras e resinas vegetais, oriundas de fontes renováveis, a fim de desenvolver um material com menor impacto ambiental. Uma conexão importante é feita por MANZINI e VEZZOLI (2011, p. 20) na qual eles apontam que "o papel do design industrial pode ser sintetizado como a atividade que, ligando o tecnicamente possível com o ecologicamente necessário, faz surgir novas propostas que sejam social e culturalmente aceitáveis".

Por fim, pode-se considerar que o design, em especial o industrial, possui uma importante relação com os materiais, sendo tão significativos que desempenham juntos um leque de funções aos produtos, assim como a durabilidade, os custos, entre outros (CALLEGARI e OLIVEIRA, 2013, p. $56)$.

Esta relação do design industrial com os materiais, mencionada acima, pode desempenhar papeis e funções por meio da economia circular, como, por exemplo, o reaproveitamento de materiais agroindustriais, resíduos propriamente ditos, descartados neste caso particular, no processo de fabricação das vassouras de piaçava.

\section{Economia Circular}

A economia circular tem chamado atenção nos últimos anos, por ser "uma economia que é restaurativa e regenerativa por princípio e que tem como objetivo manter produtos, componentes e materiais em seu mais alto nível de utilidade e valor o tempo todo, fazendo distinção entre ciclos técnicos e biológicos" (ELLEN MACARTHUR FOUNDATION, 2015, p.5). 
Neste sentido, o estudo em questão tem como objeto de pesquisa, a potencialidade dos resíduos de piaçava gerados no processo de fabricação de vassouras e suas possibilidades de gerar novos produtos. Atividade restaurativa e regenerativa, onde o que era o fim, torna-se o começo, ou seja, insumos para produção de novos produtos mais conscientes e menos impactantes ao meio ambiente.

As preocupações e práticas da Economia Circular vão ao encontro da sustentabilidade, pois diante dos problemas ambientais e a escassez de recursos, a economia e o meio ambiente devem ser considerados por meio de uma relação circular (TIOSSI et tal, 2017, p. 5). Neste sentido, é importante repensar a eliminação e utilização dos resíduos por meio da Economia Circular, visando o seu uso e aplicação no universo do design sustentável.

A Economia Circular distingue os ciclos de produção e é composta por três princípios, que se somam complementando a filosofia do "Cradle to Cradle - Do berço ao berço" onde todos os materiais envolvidos nos processos industriais retornam ao berço. No primeiro princípio, "Preservar e aprimorar o capital natural controlando estoques finitos e equilibrando os fluxos de recursos renováveis" sempre que possível a Economia Circular escolhe tecnologias e processos que utilizam recursos renováveis. No segundo princípio, "Otimizar o rendimento de recursos fazendo circular produtos, componentes e materiais no mais alto nível de utilidade o tempo todo, tanto no ciclo técnico quanto no biológico", a remanufatura, a renovação e a reciclagem são projetadas para que seus componentes continuem circulando e contribuindo para a economia. Por último, o terceiro princípio, "Estimular a efetividade do sistema revelando e excluindo as externalidades negativas desde o princípio" trata da redução de danos a sistemas e áreas como habitação, mobilidade, saúde etc., e as externalidades como o uso da terra, poluição sonora etc, (ELLEN MACARTHUR FOUNDATION, 2015, p. 7).

No "Manifesto do Design na Economia Circular" (LUZ, CESAR e BAUTISTA, 2016, pp. 20 26) indicam seis princípios para o design circular, que são:

- O seu DESIGN de produto, serviço ou modelo de negócio deve trazer soluções para melhorar a vida das pessoas e do planeta. Deve inspirar mudanças como: transformar o consumidor em usuário e o produto em serviço;

- O seu DESIGN deve ser inclusivo. Deve inspirar Brand Owners ${ }^{1}$ a gerar valor para as pessoas e a estimular consumo consciente. A cadeia produtiva deve beneficiar pessoas;

- O seu DESIGN deve estender a vida útil do produto, aumentar seu valor com o tempo e proporcionar um incentivo para o reuso, remanufatura ou reciclagem;

- O seu DESIGN deve estimular a troca de conhecimento, gerar experiências positivas e inspirar as próximas gerações;

- O seu Design deve ser imaginado como parte de um ecossistema. Ele deve buscar inspiração na natureza e deve usar menos energia na produção do resultado final;

- O seu Design deve incentivar a pesquisa de novas matérias primas. Deve considerar a utilização do material natural, durável, renovável e reciclado para o pensamento de fechamento de ciclo.

Existe uma relação complementar entre os princípios da Fundação e os do Manifesto, onde a soma dos princípios apresentados além de incentivar a pesquisa de novas matérias-primas, do início ao fim é pensado em termos de otimização, renovação e reciclagem do produto. Neste último caso, os resíduos de piaçava (das fábricas de vassouras) são considerados matéria para a criação de produtos ao invés de serem descartados no ambiente.

Neste sentido, a ELLEN MACARTHUR FOUNDATION (2015) afirma que uma economia circular se baseia nos princípios do design de resíduos e poluição, mantendo produtos e materiais em uso e regenerando os sistemas naturais. A Fundação aponta ainda que uma das características fundamentais que descrevem a Economia Circular é o "Design sem resíduo", especificando:

\footnotetext{
${ }^{1}$ De acordo com o Cambridge Dictionary, Brand significa marca e Owbers significa dono, proprietário, ou seja, proprietários de marca.
} 
Resíduos não existem quando os componentes biológicos e técnicos (ou materiais) de um produto são projetados com a intenção de permanecerem dentro de um ciclo de materiais biológicos ou técnicos, concebidos para desmontagem e ressignificação: Os materiais biológicos não são tóxicos e podem ser simplesmente, compostados. Materiais técnicos, como polímeros, ligas e outros materiais sintéticos são projetados para serem usados novamente com o mínimo de energia e maior retenção de qualidade (ao passo que a reciclagem, como normalmente entendida, resulta numa redução da qualidade e realimenta o processo como matéria prima bruta. (Ellen MacArthur Foundation, 2015).

É possível observar que a Economia Circular representa uma mudança sistêmica, proporcionando benefícios ambientais e sociais, na qual os resíduos obtêm outro significado e são reaproveitados para a formação de um novo material. Este é o momento de se pensar em mudar um sistema onde não existia outra preocupação a não ser com a produção em si, pois é necessário se preocupar com o ambiente global e o que será deixado para as gerações futuras.

Neste sentido, esta pesquisa vai ao encontro dos princípios apresentados pela Economia Circular, ao propor o estudo e desenvolvimento de um material oriundo de resíduos de fibras vegetais como a da piaçava. O design de resíduos e a geração de produtos com menor impacto ambiental permitem que seja estabelecido um laço entre produtor, empresário, reaproveitamento dos resíduos e o design industrial, mudando gradualmente a mentalidade de quem planta, vende e produz.

Por fim, vale destacar que essas sobras são oriundas de atividades humanas e podem ser reutilizadas na produção de novos produtos, evitando assim a extração de novos materiais e seu descarte em aterros sanitários. Com o olhar atento, esta matéria-prima torna-se uma preciosidade e nada é descartado, podendo ser reutilizadas e realocadas ao ciclo de consumo. Desta forma, esta pesquisa integra o conceito de Urban Mining ou Mineração Urbana, apontado por XAVIER e LINS (2018, p.23), os quais abordam os produtos e materiais reciclados pós-consumo, na forma de matériaprima secundária, minimizando assim os impactos ambientais e valorizando os resíduos. Em prol de um ambiente mais sustentável, entende-se que a matéria-prima secundária se dá pelo reaproveitamento de resíduos gerados em atividades produtivas atuais.

\section{Fibra de piaçava e seus resíduos}

Em um panorama geral, são consideradas fibras naturais, as de origem vegetal, como algodão, juta e sisal que em sua composição têm celulose e as de origem animal, como a lã e a seda que consistem basicamente em proteínas (LION FILHO, 2013, p.23). São muitas as fibras naturais vegetais, algumas são mais utilizadas e se tornam populares, como rami, coco, juta, sisal, licuri, curauá e piaçava (LEÃO, 2008, pp.26-34).

A piaçava é uma fibra natural extraída de várias palmeiras. No Brasil é explorada desde o período colonial sendo a Bahia responsável por $95 \%$ do total da produção nacional. A exploração das piaçaveiras nos Estados da Bahia, Amazonas e Pará é uma atividade puramente extrativista, por isso existe a necessidade de um manejo racional para que sua sobrevivência seja garantida (AQUINO, et al 2000).

O destaque neste artigo vai para as fibras de piaçava e seus resíduos gerados a partir da produção de vassouras, que mesmo sendo fibras originárias do Nordeste em sua maioria, são comercializadas em outras regiões brasileiras como é o caso da piaçava produzida na Bahia, mas com significativa comercialização no Estado do Rio de Janeiro e Minas Gerais (GLOBO RURAL, 2018).

Para MOREAU (1997), apud AQUINO, D’ALMEIDA e MONTEIRO (2002, p.2) a adaptação da piaçava em solos de baixa fertilidade está entre as suas principais características e seu tempo de vida é de até 20 anos. Antes de abordar especificamente as fibras de piaçava, é importante conhecer as características da palmeira Attalea funifera martius.

GUIMARÃES e SILVA (2012, p.51) ao pesquisarem sobre a piaçava da Bahia, informam que o caule desde o subterrâneo tem de 1,5 até $15 \mathrm{~m}$ de altura e 20 a $30 \mathrm{~cm}$ de diâmetro, com uma planta adulta apresentando em média de 5 a 10 folhas, podendo atingir um número maior. Os autores citam também VINHA e SILVA (1998) ao especificar que as folhas podem alcançar 9 metros de comprimento total. A Figura 1 ilustra o aspecto da palmeira. 


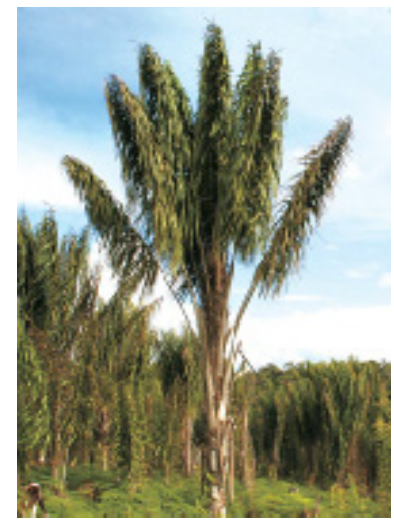

Figura 1: Palmeira da espécie Attalea funifera martius. Fonte: GUIMARÃES e SILVA (2012, p.48).

Embora existam outras espécies de palmeiras que dão origem a piaçava, este estudo utiliza os resíduos das fibras da Attalea funifera martius utilizadas na fabricação de vassouras de piaçava. Os autores acima mencionam que em qualquer época do ano é possível realizar a coleta da fibra, porém a mesma é feita uma única vez, com rendimento por pé de 8 a 10 quilos de fibra por ano, medindo até 4 metros de comprimento e cerca de 1,1 milímetro de espessura. Entre as etapas da coleta (Figura 2A, $2 \mathrm{~B}$ e $2 \mathrm{C}$ ) até o destino final, o processo requer que as fibras sejam estendidas para secagem, garantindo que sequem uniformemente. Em seguida são limpas para retirada dos resíduos e posteriormente amarradas em fardos, com possibilidades de cortes e envio para a indústria.
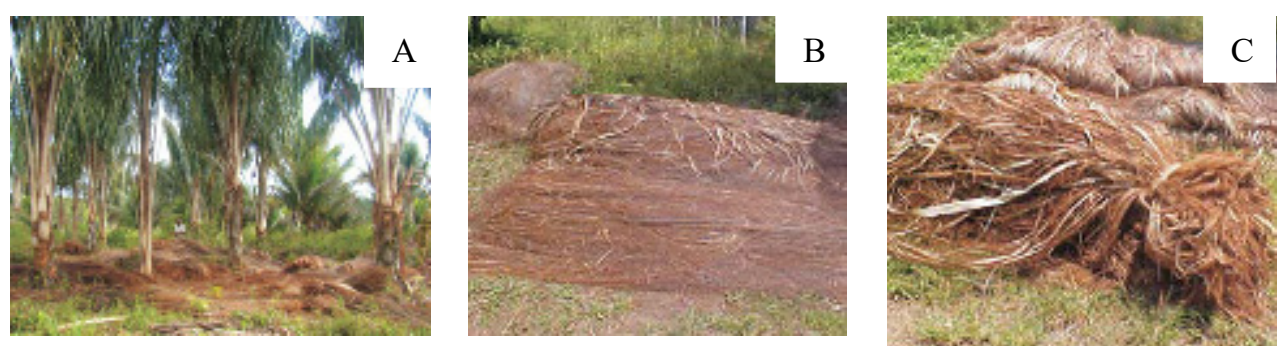

Figura 2: Piaçava colhida (a); fibra de piaçava (b) e borra (c) Fonte: GUIMARÃES e SILVA (2012, p.170).

A colheita da fibra é feita a partir da obtenção de cada nova folha da piaçaveira, que é seguida por uma fita onde estão contidas as fibras. A Figura 3 (A, B e C) ilustra a relação de diferença entre a capa, o toco e a fita, onde a capa é um tipo de cobertura vegetal que envolve as fibras e as fitas (utilizadas nos pentes de piaçava para confecção de cobertura para quiosques). Os tocos são fragmentos de capas que foram cortadas e deixadas para serem aproveitadas na próxima extração (PIMENTEL,2015, p. 53).
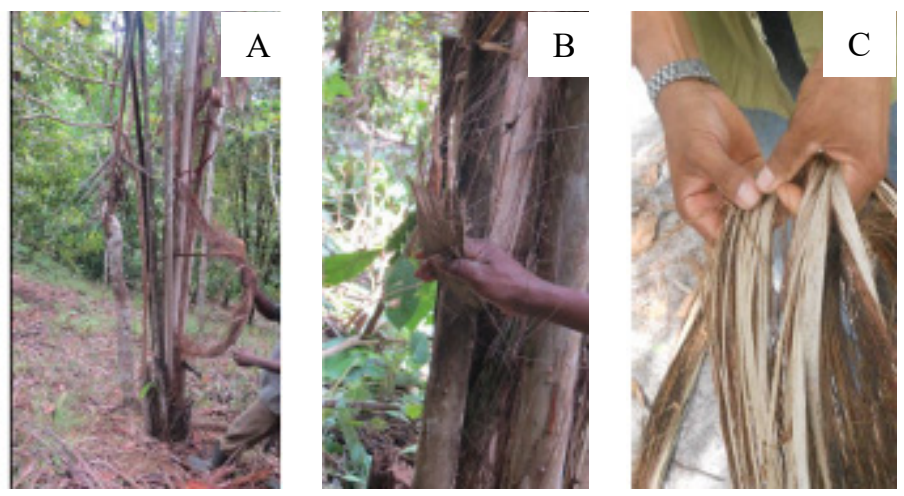

Figura 3: A capa (A); toco na planta (B); a capa de fibra bruta (C) Fonte: PIMENTEL $(2015$, p. 53) 
Para os autores, GUIMARÃES e SILVA (2012, p.169):

Os fios da piaçava ficam a princípio, colados no pecíolo e em quase toda a extensão da nervura central da fibra [...] A fibra "borra" que é coletada junto com a fibra piaçava, se assemelha a um papel ralo que deixa as fibras juntas. Geralmente a borra equivale a aproximadamente $20 \%$ do total da fibra de piaçava colhida. (GUIMARÃES e SILVA, 2012).

A literatura mostra que após a colheita, as fibras serão limpas e separadas da borra, cortadas em fardos para a comercialização. Segundo LION FILHO (2013, p.18), o percentual de desperdício nas indústrias que trabalham com a fibra de piaçava gira em torno de $20 \%$.

Em um estudo feito por SAVASTANO JUNIOR e PIMENTEL (2000), foi observado que no processo de limpeza e penteamento da fibra, em torno de $30 \%$ de refugo, que são queimados ao ar livre, podem ser aproveitados. Outro resíduo de fácil aproveitamento vem das fábricas de vassouras, onde as fibras com menos de $50 \mathrm{~cm}$ de comprimento são descartadas. Para os autores há poucas informações sobre a destinação de resíduos. Eles salientam ainda que é quase inexistente a prática dos chamados banco de resíduos (SAVASTANO JUNIOR e PIMENTEL, 2000, p. 22). É importante atentar para as oportunidades de uso dos resíduos da piaçava para além de adubo, da incineração e do descarte. É preciso pensar no reaproveitamento desses resíduos como uma alternativa tecnológica que impulsione a geração de renda e traga benefícios econômicos e ambientais por meio da sustentabilidade. O trabalho com piaçava gera resíduos em dois momentos, o primeiro no beneficiamento da fibra, enquanto o segundo na produção de vassouras.

Atualmente a piaçava é utilizada em grande parte na fabricação de vassouras, escovas, cordas para navios, cestos, capachos e coberturas. A fibra da piaçava tem aproximadamente $14 \%$ de umidade, $0,8 \%$ de resíduo mineral, $0,7 \%$ de extrativos, $45 \%$ de lignina e $28,6 \%$ de celulose. A análise dos elementos presentes nas fibras mostra $54,5 \%$ de carbono, $5,84 \%$ de oxigênio e $0,52 \%$ de nitrogênio. Por estas características a piaçava poderia ser utilizada como reforço em compósitos (AQUINO et al., 2000, p. 19603).

Segundo LEÃO (1997) citado por AQUINO et al (2000, p.19603), os compósitos lignocelulósicos correspondem a uma área da ciência dos materiais em crescente expansão. As fibras naturais, em abundância no nosso país, se forem direcionadas para investimentos em novos materiais compósitos, podem conter o êxodo rural e impulsionar o crescimento econômico no setor agrícola. A ISO 14000 proporciona a esses compósitos a chance de serem considerados não somente como uma alternativa isolada, mas também uma estratégia para reduzir problemas ambientais.

Neste contexto, para conhecimento do processo produtivo de vassouras e coberturas e por consequência da geração de resíduos de piaçava, foram realizadas visitas técnicas em fábricas com a descrição do processo de utilização da fibra de piaçava na fabricação de vassouras.

Durante o primeiro semestre de 2019 foram visitadas três empresas no Rio de Janeiro que trabalham com a fibra de piaçava - duas na fabricação de vassouras e uma na confecção de coberturas - ambas permitiram acompanhar o processo de fabricação desses produtos. A ordem de visitação se deu da seguinte forma:

Empresa Divino Piaçava - Localizada na Rua Óbidos, no 141, Vila Valqueire - RJ. A empresa trabalha especificamente com a palha da piaçava na confecção de pentes ${ }^{2}$ para aplicação em coberturas de quiosques, varandas, etc. Possui 7 funcionários e sua produção é referência nesse tipo de produto. A visita foi realizada no dia 03 de março de 2019 e ao final da entrevista foi possível recolher amostras da palha de piaçava, mesmo não sendo este resíduo utilizado para a formulação do compósito em questão.

Segundo relato da proprietária, este tipo de fibra somente é utilizada na confecção de "pentes" destinados a coberturas, com ripas que medem em torno de 2 metros e são aplicadas diretamente sobre a estrutura do telhado. Após a montagem da cobertura, as pontas do caimento são acertadas com uma tesoura, para que o acabamento se apresente uniforme. A Figura 4 (A e B) ilustra o depósito com as palhas (ou borras) de piaçava da empresa Divino Piaçava e a Figura 5 (A e B) a sua aplicação em coberturas.

\footnotetext{
${ }^{2}$ Confecção artesanal onde a palha de piaçava é amarrada em tiras, preenchendo toda a ripa de madeira para aplicação de coberturas. Fonte: Autor, 2019.
} 

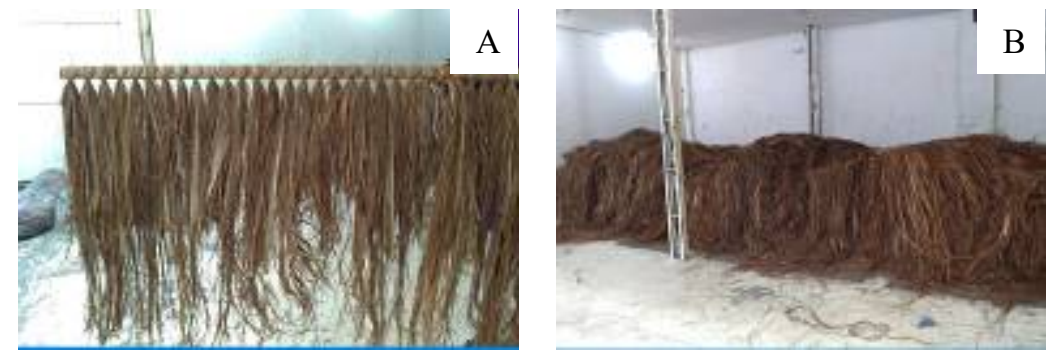

Figura 4: Palhas amarradas nas ripas (A) e depósito com as ripas Fonte: Autor, 2019.
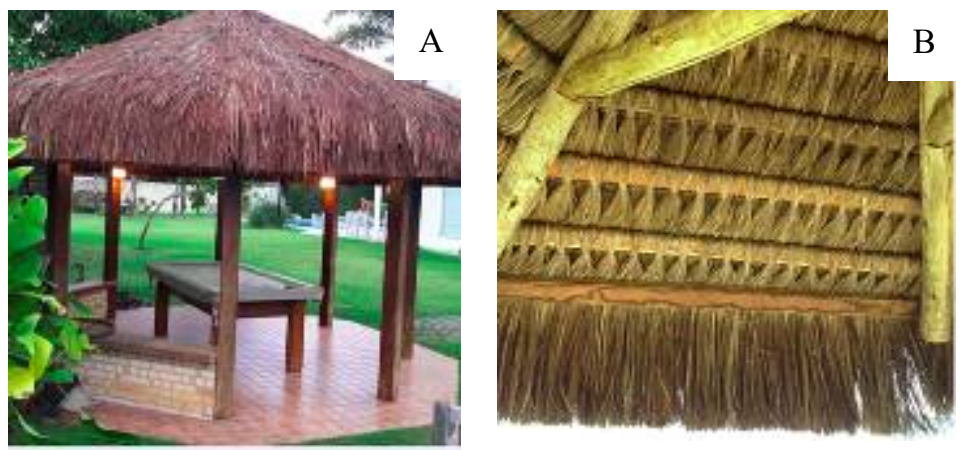

Figura 5: Aplicação das palhas de piaçava: quiosque (A) e detalhe (B). Fonte: Divino Piaçava, 2019.

Associação Aliança dos Cegos - Localizada na Rua 24 de Maio, n 47, São Francisco Xavier - RJ, na qual a finalidade é amparar e readaptar deficientes visuais adultos. A AAC emprega pessoas videntes $^{3}$ e deficientes visuais. Os recursos financeiros advêm de associados mantenedores e os produtos, tais como vassouras, rodos e espanadores são produzidos na própria associação. A visita foi realizada no dia 16 de abril de 2019, com recolhimento de amostras da fibra de piaçava, da bacina ${ }^{4}$ e dos resíduos produzidos na fabricação das vassouras. Atualmente a produção de vassouras é realizada por dois funcionários videntes. A Figura $6(\mathrm{~A}, \mathrm{~B}, \mathrm{C}$ e D) ilustra as etapas de produção da vassoura, onde o início acontece com a separação das fibras, bacina e piaçava, ocorrendo em seguida o penteamento, momento no qual já ocorre o acúmulo de resíduos das fibras que são descartadas.

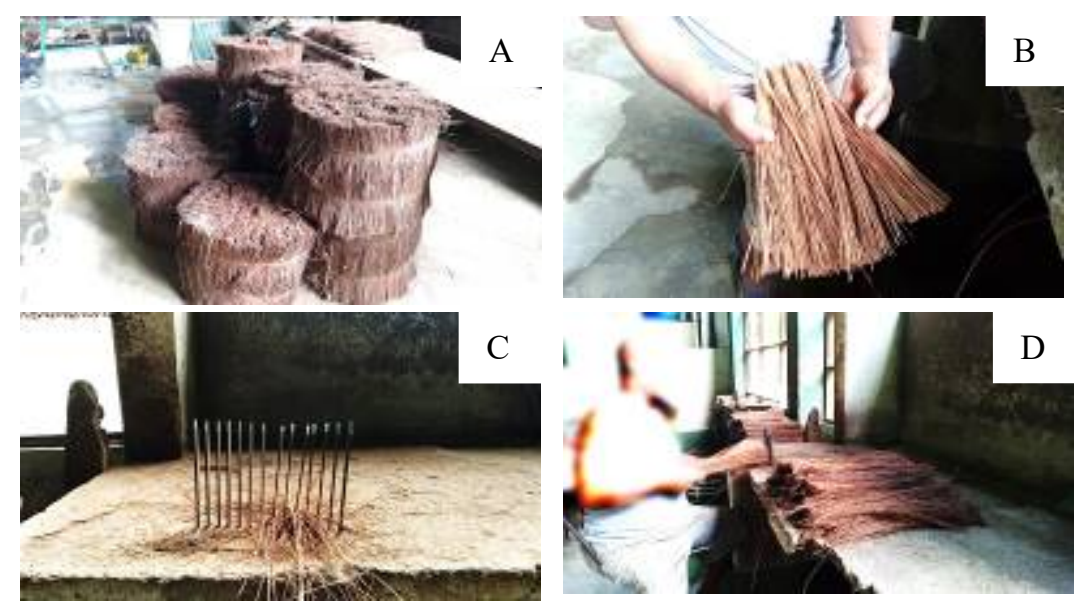

Figura 6: Fibras em fardos (A); soltas (B); pente (C) e penteamento das fibras (D).

Fonte: Autor, 2019.

\footnotetext{
${ }^{3}$ Pessoa que vê, em contraposição a pessoa cega. Dicionário Priberam da Língua Portuguesa (2008-2020).

${ }^{4}$ Segundo JOSA (2008, p. 40), a bacina é uma fibra mais leve que tem a função de engrossar, dar volume a vassoura.
} 
O penteamento é a etapa onde a fibra é limpa, eliminando possíveis insetos, como besouros que vivem nas palmeiras. No ato de separar e padronizar as fibras, em consequência uma parte é descartada, como ilustra a Figura 7, sem nenhum aproveitamento.

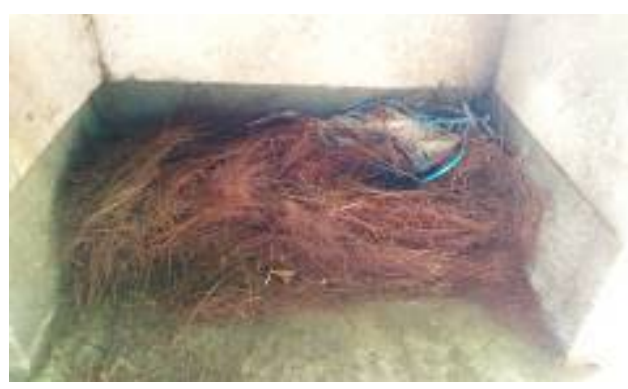

Figura 7: Resíduos do penteamento.

Fonte: Autor (2019)

Após o penteamento, é preciso molhar a piaçava para moldá-la na prensa, presa em uma base de madeira que serve de reforço para pregar-se a lata junto às fibras, finalizando o processo de fabricação da vassoura, ilustrada na Figuras 8 (A,B,C e D). Na etapa seguinte, é dado o acabamento na guilhotina, no qual são eliminados cerca de 3 centímetros das fibras salientes (Figura 9).
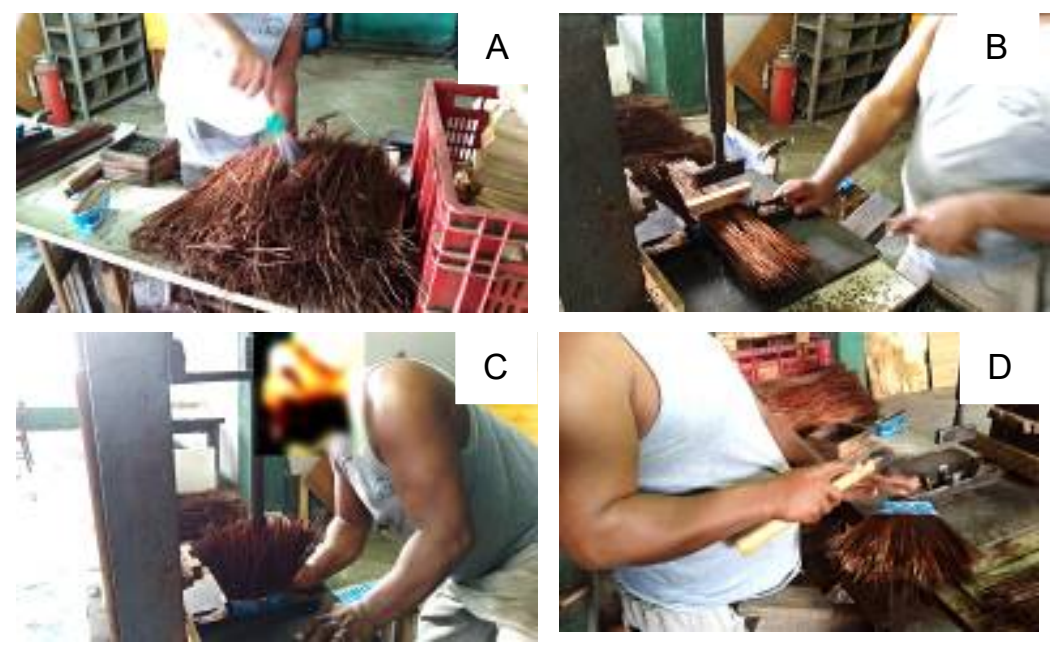

Figura 8: Umedecimento (A); prensagem (B e C) e fibras na lata (D) Fonte: Autor, 2019.

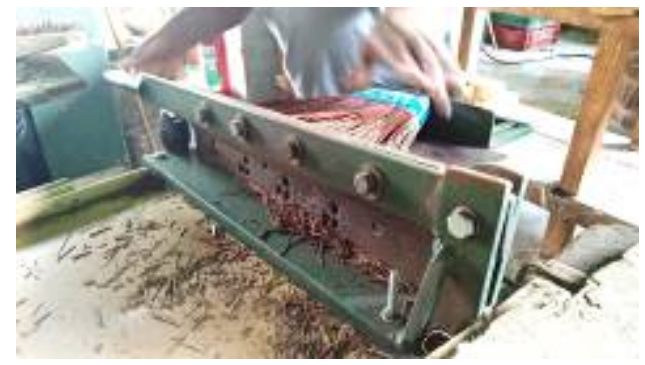

Figura 9: Acabamento na guilhotina Fonte: Autor, 2019.

Nesta fábrica, por apresentar um número menor de funcionários e produção reduzida, não souberam informar a quantidade aproximada de resíduos descartados bem como seu tempo de acúmulo. 
Vassouras Irajá - Localizada na Rua Pedro Teixeira, $n^{\circ} 556$, Irajá - RJ, a visita foi realizada no dia 16 de abril de 2019, recolhendo-se amostras da fibra de piaçava, da bacina e dos resíduos produzidos na fabricação das vassouras. Seu quadro funcional consiste em um número de 8 trabalhadores. Quanto à produção é uma empresa que confecciona uma grande quantidade de vassouras, aproximadamente 50 dúzias diariamente, ou seja, 600 vassouras produzidas todos os dias, o que gera um volume considerável de resíduos. O trabalho é realizado diretamente com as fibras de piaçava (Figura $10 \mathrm{~A}, 10 \mathrm{~B}, 10 \mathrm{C}$, e $10 \mathrm{D}$ ), sendo tal empresa reconhecida no mercado regional pela qualidade do material produzido.
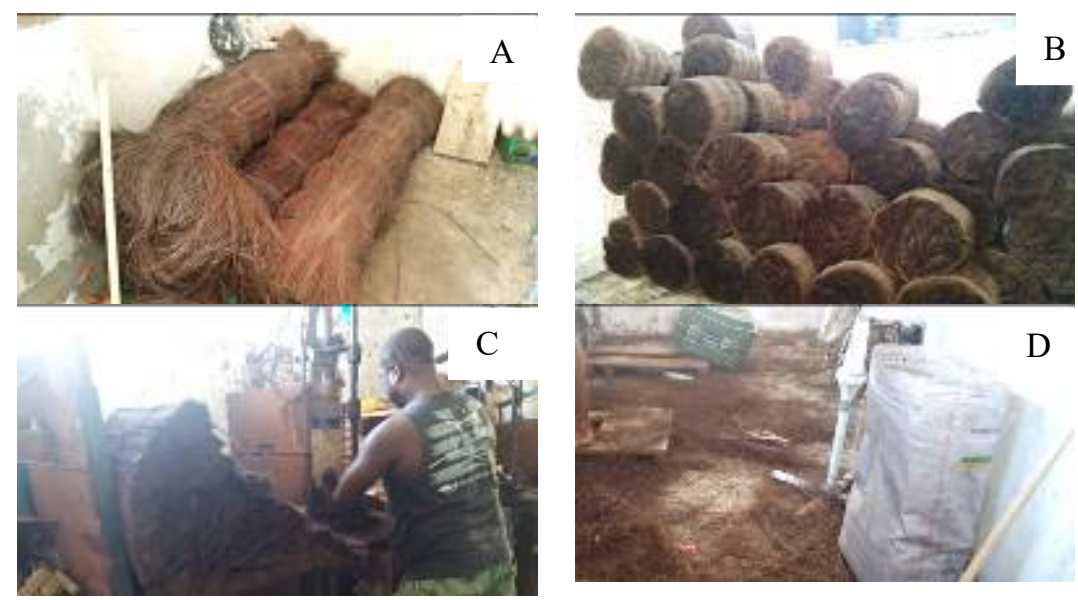

Figura 10: Fibra sem tratamento (A); em rolos (B); fabricação (C) e resíduos (D). Fonte: Autor, 2019.

Devido à fábrica Vassouras Irajá ter uma produção maior e fornecer piaçava para outras fábricas do Estado do Rio de Janeiro, a mesma é referência neste ramo, comprando grandes quantidades de fardos (Figura 11 A e 11 B) diretamente da Bahia. Sua produção gera um mínimo de 4 sacos de 300 litros de resíduos por dia, conforme ilustra a Figura 12 (A e B) e por esta razão as amostras utilizadas para a formação do ecocompósito da pesquisa foram obtidas desta empresa.
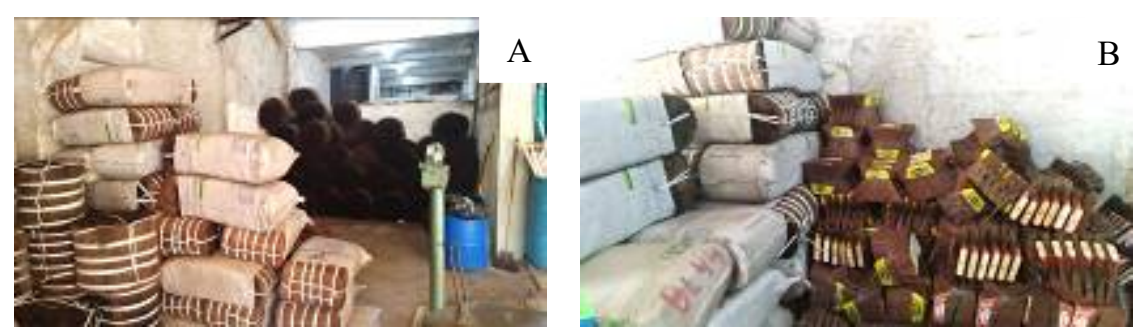

Figura 11: Piaçava e bacina armazenadas (A) e a produção final (B) Fonte: Autor, 2019.
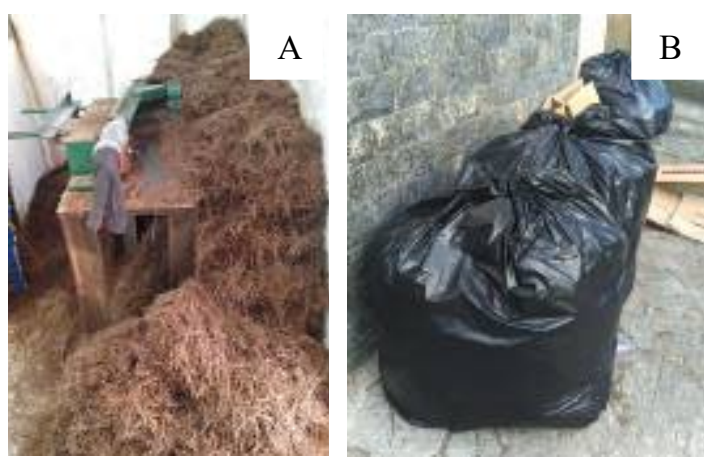

Figura 12: Resíduos gerados na guilhotina (A) e o descarte (B) Fonte: Autor, 2019. 
Há uma variação no comprimento das fibras de piaçava tidas como resíduos, ilustrada na Figuras 13 (A e B), com variação de $1 \mathrm{~cm}$ a $11 \mathrm{~cm}$. Esses resíduos são tratados pelos fabricantes como material sem utilização, isso ocorre devido à falta de conhecimento, mão-de-obra e/ou tempo para produção de outro produto. Sendo assim este resíduo será analisado em relação a sua potencialidade enquanto matéria-prima no design sustentável.

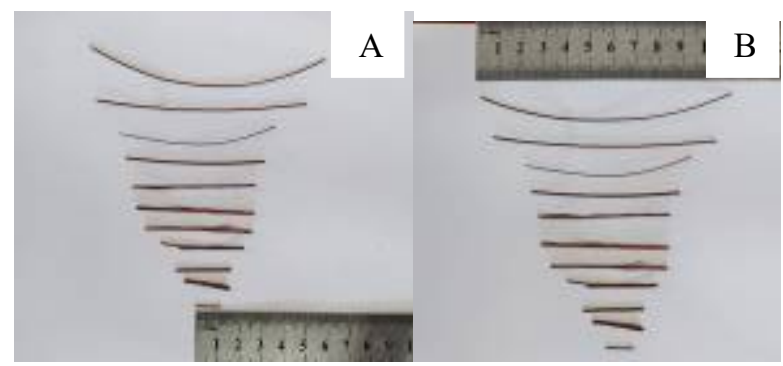

Figura 13: Resíduos com variação de tamanho. Fonte: Autor, 2019.

É importante mencionar que durante as visitas nas duas fábricas, $A A C$ e a Vassouras Irajá, foi relatado o uso da bacina, que também é uma fibra de piaçava, porém, originária do médio Rio Negro (Manaus). Por ser mais leve, é utilizada no preenchimento e volume do núcleo da vassoura, enquanto a piaçava da Bahia, ao contrário é mais grossa e resistente, proporcionando firmeza à estrutura externa no conjunto de fibras. A Figura 14 mostra a diferença entre a bacina que é mais volumosa e um pouco disforme (A e B), enquanto a piaçava é mais uniforme e com menos volume (C e D).
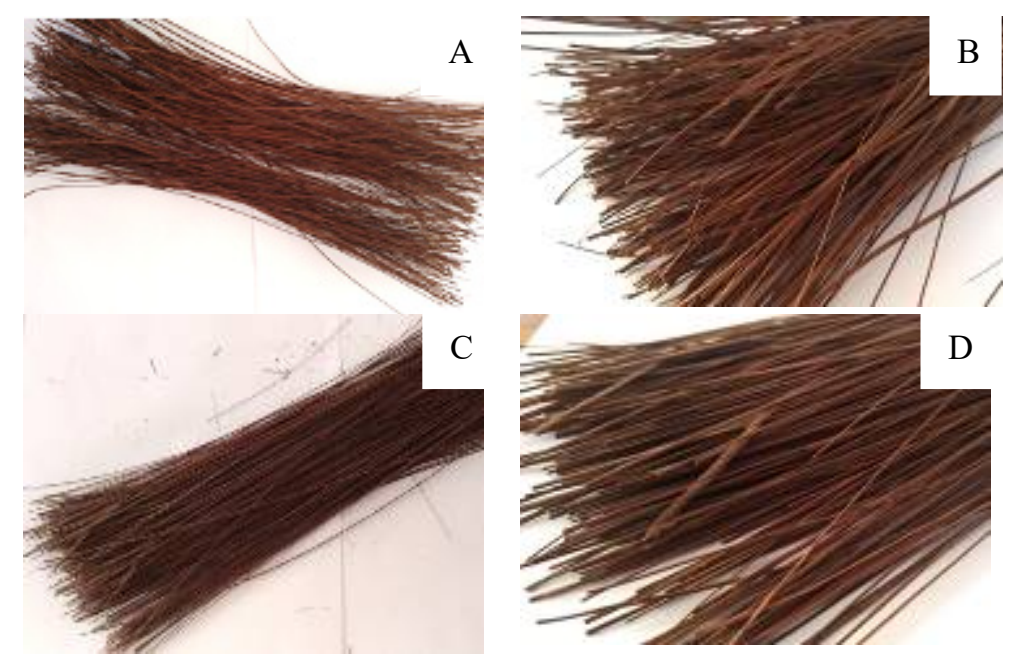

Figura 14: Bacina (A e B) e piaçava penteada (C e D).

Fonte: Autor, 2019.

A presença das duas fibras (piaçava e bacina) foram identificadas nos resíduos, simultaneamente durante a etapa inicial, com o penteamento e durante o acabamento da vassoura, etapa final. Esses resíduos não são separados durante a fabricação das vassouras e ambos foram utilizados na confecção do compósito.

O compósito desenvolvido a partir do uso dos resíduos das fibras de piaçava e bacina em matriz polimérica de origem vegetal se traduz em um estudo contextualizado no design sustentável. Estão sendo realizadas experimentações com o material, analisando-se seu comportamento por meio da usinagem, características mecânicas e propriedades sensoriais. Ao final, esta pesquisa de Mestrado pretende contribuir com o cenário mais consciente no universo das criações da Economia Circular.

Neste sentido, LEFTERI cita que uma das forças motoras do desenvolvimento dos materiais é a necessidade de fontes sustentáveis. 
O século XX será lembrado como um tempo em que as noções clássicas de produção tiveram como referência os plásticos derivados do petróleo. O próximo século poderá ser aquele em os plásticos e produtos não mais sairão das máquinas, mas crescerão ou serão cultivados. A necessidade urgente de encontrar materiais rapidamente renováveis está levando os designers a fazer experimentos com materiais de descarte (LEFTERI, 2017. p.13)

Ao final da fase de experimentação com o ecocompósito desenvolvido nesta pesquisa, serão estudadas as suas possíveis aplicações no campo do design.

\section{Considerações finais}

Este artigo apresenta caminhos que relacionam o design, a economia circular e a materialidade em conjunto para a ideia de reaproveitamento de resíduos agroindustriais oriundos das fábricas de vassouras de piaçava. Parte do processo desta pesquisa se deu com visitas técnicas, recolha e análises dos resíduos recolhidos. Enquanto material de reforço em matrizes poliméricas de origem vegetal, os resíduos da piaçava podem apresentar potencial para aplicação em produtos menos agressores ao meio ambiente.

Segundo a literatura, a fibra de piaçava apresenta boas características físico-mecânicas e potencial para uso e aplicações diversas, sendo o design convidado a contribuir para este cenário mais sustentável.

\section{Design, Materials and Circular Economy: relations with piassava fiber}

\section{Abstract:}

This article aims to present piassava fiber, especially its residues, as a material resource in the field of sustainable design and circular economy. This text is part of a master's research in progress in the Graduate Program in Design at the Federal University of Rio de Janeiro. It is presented and discussed the process of manufacturing brooms from this fiber and in particular, the generation of residues from piassava, which can become an alternative resource in the development of artifacts that are less harmful to the environment. The relevance of this study is the reflection on the use of residues from plant sources in the manufacture of new materials, in particular, eco-composites of polymeric matrix from renewable sources, finally analyzing their use in the generation of sustainable design products. Piassava fiber is analyzed from the perspective of sustainable design and the circular economy, resulting in a study of positive impacts for the environment and society in general.

\section{Keywords:}

Industrial design; Materials; Piassava fiber; Vegetable fiber waste; Circular economy

\section{Referências bibliográficas}

AQUINO, R.; D'ALMEIDA, J.; MONTEIRO, S. Desenvolvimento de compósitos de matriz polimérica e piaçava, como substitutivo de produtos de madeira, n1, ano 4, 2002 . Disponível em: <https://www.semanticscholar.org/paper/DESENVOLVIMENTO-DE-COMP\%C3\%93SITOS-DEMATRIZ-POLIM\%C3\%89RICA-Aquino-D'almeida/013f80c84ae8a9c055e1af3717e6aa63a8c58fa7> Acesso em: 07 de Ago. 2018.

AQUINO, R.; D'ALMEIDA, J.; MONTEIRO, S. Desenvolvimento de compósitos de matriz polimérica e piaçava. Congresso Brasileiro de Engenharia e Ciência dos Materiais, 14. 2000. São Pedro, SP. Anais, p.19601-19611. 
ASHBY, Michael F.; JOHNSON, Kara.Materiais e Design: Arte e Ciências da Seleção de Materiais do Design do Produto. 2. ed. Rio de Janeiro: Campus, 2011.

CALEGARI, E.P.; OLIVEIRA, B. F de. Um estudo focado na relação entre design e materiais. Projética, v.4, n.1, Jan./Jun. 2013. Disponível em: <http://www.uel.br/ revistas/uel/index.php/projetica/article/view/14348. Acesso em: 10 de Nov. 2018.

CALLISTER, JR. W.D. Ciência e engenharia dos materiais: uma introdução. Tradução Sério Murilo Stamile Soares. Revisão técnica Paulo Emílio Valadão de Miranda. 5a Ed. Rio de Janeiro: LTC Livros Técnicos e Científicos Editora S.A. 2002.

CORRÊA, H.; XAVIER, L. Concepts, design and implementation of Reverse Logistics Systems for Sustainable Supply Chains in Brazil. Journal of Operations and Supply Chain Management, v6, n.1, pp.1-25, Jan/Jun 2013. Disponível em:

<http://citeseerx.ist.psu.edu/viewdoc/download?doi=10.1.1.902.6379\&rep=rep1\&type=pdf. $>$ Acesso em: 15 de Jul. 2019.

COHEN, M. Materials and Man's Needs Summary Report of the Committee on the Survey of Materials Science and Engineering, Washington: National Academy of Science, 1974. Disponível em: <https://www.nap.edu/catalog/10435/materials-and-mans-needs-materials-science-andengineering >. Acesso em: 09 de Ago. 2019.

DIAS, M.R.A.C Percepção dos materiais pelos usuários: modelo de avaliação Permatus. 2009. Tese (Doutorado em Engenharia e Gestão do Conhecimento). Universidade Federal de Santa Catarina. Florianópolis. 2009.

ELLEN MACARTHUR FUNDADION. Economia Circular. 2010. Disponível em: <https://www.ellenmacarthurfoundation.org/pt/economia-circular-1/conceito > . Acesso em: 24 de Jun.2019.

LEFTERI, Chris. Materiais em design. Tradução de Henrique Eise Toma. - São Paulo: Blucher, 2017. 256p.:il., color.

GIACOMINI, N. P. Compósitos reforçados com fibras naturais pra a indústria automobilística. 2003. Dissertação (Mestrado em Ciências e Engenharia de Materiais). Universidade de São Paulo. São Carlos. 2003.

GOMES FILHO, J.G. Design do Objeto - Bases Conceituais. São Paulo: Escrituras Editora, 2006.

GLOBO RURAL. Piaçava vira lavoura comercial no Sul da Bahia. Disponível em: $<$ https://g1.globo.com/economia/agronegocios/globorural/noticia/2018/11/25/piacava-vira-lavouracomercial-no-sul-da-bahia.ghtml.>. Acesso em: 26 de Nov. 2018.

GUIMARÃES, C.A.L.; SILVA, L.A.M. Piaçava da bahia (Attalea funifera martius: do estrativisto a cultura agrícola. Bahia: EDITUS - Editora da UESC.2012.

LEÃO, M.A..Fibras de licuri: um reforço vegetal alternativo de compósito polimérico. 2008 Dissertação (Mestrado em Ciência e Engenharia de Mecânica). Universidade Feredal do Rio Grande do Norte. Natal, 2008.

LEÃO, A.L., Carvalho, F.X., Frollini, E., Lignocellulose-Plastics Composites - UNESP, 1997.

LION FILHO, C. A. P. Q. Desenvolvimento e caracteretização de compósitos a partir da borra da piaçava para construção da parábola de um fogão solar a concentração. 2013. 197f.Tese (Doutorado em Ciencia e Engenharia de Materiais). Universidade Federal do Rio Grande do Norte. Natal, 2013.

LUZ, B.; CESAR, K.; BAUTISTA, R. Manifesto do Design na Economia Circular. 2016. Disponível em: <http://www.redbandana.com.br/manifesto Design EcoCircular.

pdf > . Acesso em: 1 de Set. 2019.

MANZINI, E.; VEZZOLI, C. O Desenvolvimento de Produtos Sustentáveis. Tradução de Astrid de Carvalho. 1 ed. 3.reimp - São Paulo: Editora da Universidade de São Paulo, 2011.

SAVASTANO JUNIOR. H; PIMENTEL, L.L. Viabilidade do aproveitamento de resíduos de fibras vegetais para fins de obtenção de material de construção. Revista Brasileira de Engenharia 
Agrícola e Ambiental, v.4, n.1, pp.103-110, Jan./Abr. 2000. Disponível em:

$<$ www.scielo.br/scielo.php?pid=S1415-43662000000100019\&script=sci_abstract\&tlng=pt $>$. Acesso em: 19 de Jul. 2019.

TIOSSI, F. M; SIMON, A. T.; TERNERO, E. M Sustentabilidade e economia circular: um estudo sistemático da literatura na última década, 2017. Disponível

em:<http://engemausp.submissao.com.br/19/anais/arquivos/272.pdf>. Acesso em: 14 de Jun. 2019.

UOL. Dia do consumo consciente tem como ser sustentável sem deixar de comprar, 2011. Disponível em <https://economia.uol.com.br/ultimasnoticias/

infomoney/2011/10/14/dia-do-consumo-consciente-tem-como-ser-sustentavel-sem-deixar-decomprar.htm>Acesso em: 02 de Mai. 2020

XAVIER, L.H; LINS, F.A.F. Mineração Urbana de resíduos eletrônicos: uma nova fronteira a explorar no Brasil. Brasil Mineral, no 379,p.23. Mar.2018. Disponível em:

<https://www.cetem.gov.br/images/periodicos/2018/mineracao-urbana.pdf>. Acesso em: 04 de set de 2020.

WALTER, Y. O conteúdo da forma: subsídios para seleção de materiais e design, Dissertação (Mestrado em Desenho Industrial). Universidade Estadual Paulista. Bauru, 2006. 